\title{
ESTABILIDADE DE SUCO DE UVA EM PÓ MICROENCAPSULADO POR ATOMIZAÇÃO
}

\author{
T. C. B. GALLO ${ }^{1 *}$, P. MOSER ${ }^{1}$, V. R. N. TELIS ${ }^{1}$ \\ ${ }^{1}$ Universidade Estadual Paulista, Departamento de Engenharia e Tecnologia de \\ Alimentos \\ *e-mail: thacbenatti@gmail.com
}

\begin{abstract}
RESUMO
A elaboração do suco de uva em pó representa uma alternativa interessante no sentido de melhorar a conservação do produto, sendo a produção de sucos de frutas em pó uma aplicação de crescente interesse industrial. O produto seco apresenta um aumento da sua vida útil e maior disponibilidade, porém, o processo de atomização é dificultado devido ao comportamento pegajoso que as frutas exibem quando submetidas às variações de umidade e temperatura. É de grande importância para a indústria melhorar o desempenho do processo de secagem por atomização, a fim de obter produtos com melhores características, bem como aumentar o rendimento. Uma alternativa para otimizar o processo é adicionar agentes carreadores, que também possuem a função de encapsulantes. O objetivo deste trabalho foi avaliar a estabilidade e qualidade de sucos de uva em pó obtidos através spray drying, utilizando combinações de maltodextrina (MD) com proteína isolada de soja (SPI) ou proteína concentrada de soro de leite (WPC) como agentes carreadores, visando a proteção das antocianinas e obtenção de um produto com boa estabilidade. A amostra SPI 1, após 90 dias de exposição à luz, apresentou maior retenção de antocianinas, com perda de apenas $28 \%$ do conteúdo inicial, com menor ganho de umidade e menor variação na coloração do suco em pó. A utilização desses agentes carreadores resultou em pós mais estáveis ao armazenamento, sendo promissores como encapsulantes.
\end{abstract}

\section{INTRODUÇÃO}

A produção de suco de uva no Brasil encontra-se em ascensão, impulsionada, principalmente, pelo aprimoramento tecnológico. De janeiro a abril de 2015, a comercialização de suco de uva no mercado interno foi de 39.510.190 litros, mostrando um aumento de 4,6\% em relação ao mesmo período no ano de 2014 (UVIBRA, 2015). No ano de 2014, a comercialização de suco de uva no mercado interno foi de 122.866.288 litros, resultando em um aumento de 10,83\% em relação a 2013, mostrando um forte crescimento nesse ramo.

A uva da cultivar BRS Violeta, desenvolvida pela Embrapa Uva e Vinho, foi obtida a partir de cruzamento 'BRS Rúbea' $\mathrm{x}$ 'IAC 1398-21' em 2006. Ela contém altos níveis de antocianinas e é considerada uma alternativa para produzir sucos com coloração intensa e ricos em antioxidantes (REBELLO 
et al., 2013). A presença das antocianinas tem aumentado o destaque dado à uva e seus derivados, devido à seus diversos benefícios para a saúde e por ser considerada uma importante fonte de pigmentos naturais.

A secagem por spray drying é uma alternativa para produzir sucos de uva em pó com grande quantidade de antocianinas. Porém, durante a secagem, os pós costumam apresentar problemas de manipulação, como pegajosidade (stickness) e alta higroscopicidade. Esses problemas tornam o armazenamento e utilização mais difícil, além de diminuir o rendimento do processo e afetar as características do produto final. Uma alternativa para evitar aderência e a pegajosidade é a adicionar agentes carreadores com alta massa molar, que melhoram a estabilidade do material durante a secagem e o armazenamento e, além disso, desempenham a função de encapsulantes (TELIS; MARTINEZ-NAVARRETE, 2010). A microencapsulação é uma técnica importante para conservar compostos bioativos, como as antocianinas, que são instáveis durante o processamento e armazenamento.

Agentes carreadores, como maltodextrina, proteínas de soja e proteína de soro, facilitam a secagem de alimentos por spray drying (KANDANSAMY; SOMASUNDARAM, 2012) e também atuam como material de parede. Ele atuam protegendo o material das condições adversas do meio, como por exemplo, luz, umidade, oxigênio e interações com outros compostos, estabilizando o produto e aumentando a sua vida útil. A maltodextrina apresenta uma boa relação entre custo e eficácia, possui boa solubilidade e baixa viscosidade, mesmo em altas concentrações. A capacidade da maltodextrina em proteger $\mathrm{O}$ material encapsulado é atribuída à formação de filme e as propriedades plásticas. As proteínas possuem excelentes propriedades como viscosidade, emulsificação e capacidade de formação de filme (MADENE et al., 2006). A mistura de proteínas e carboidratos favorece a proteção de compostos ativos e combina propriedades específicas de cada polímero (NESTERENKO et. al., 2013). Charve e Reineccius (2009) verificaram que ao usar isolados proteicos de soro e de soja como material de parede, eles previnem a oxidação do material de recheio durante o armazenamento.

Considerando que a uva apresenta uma grande quantidade de antocianinas e levando em conta o fato de que esses compostos são instáveis durante $\mathrm{o}$ processamento $\mathrm{e}$ armazenamento, a microencapsulação do suco de uva pode representar uma técnica promissora no sentido de melhorar a estabilidade desses pigmentos.

Com base nas considerações anteriores, o objetivo deste trabalho foi à obtenção de suco de uva em pó, através da secagem em spray drying, utilizando misturas de maltodextrina com proteína de soro ou de soja como agentes carreadores, visando a proteção das antocianinas e a obtenção de um produto com boa estabilidade em relação a alterações físicas e químicas. Para isso foram determinadas as isotermas de sorção e a pegajosidade dos sucos em pó. Foi avaliada a estabilidade durante o armazenado com a incidência de luz.

\section{MATERIAIS E MÉTODOS}

\subsection{Materiais}

O suco de uva foi obtido da variedade BRS Violeta (Vitis labrusca), adquirido na EMBRAPA (Jales, Brasil). Os agentes carreadores utilizados foram maltodextrina DE-10 MOR-REX 1910 (Corn Products, Brasil), proteína isolada de soja (Tovani Benzaquen, Brasil) com 92,8 \% de proteína e proteína concentrada de soro de leite (Alibra Ingredientes Ltda, Brasil) com conteúdo proteico de $80 \%$. 


\subsection{Métodos}

\subsubsection{Preparo das amostras}

O suco de uva foi produzido em panela extratora a vapor, e armazenado em câmara frigorífica à $-18{ }^{\circ} \mathrm{C}$, ao abrigo da luz até o seu uso. Os sólidos solúveis foram determinados em refratômetro.

Proteína isolada de soja (SPI) ou proteína concentrada de soro (WPC) foram misturados com maltodextrina (MD) e adicionadas ao suco de uva em diferentes concentrações de agente carreadores (CAC, g de carreador/g sólidos solúveis do suco) e proporções de proteína ( $\mathrm{g}$ de proteína/100 g de agente carreador). A composição dos materiais diferentes está apresentada na Tabela 1. As misturas foram adicionadas ao suco sob agitação magnética, até completa dissolução.

Tabela 1 - Composição dos materiais de parede com diferentes concentrações e proporções de proteínas.

\begin{tabular}{lcc}
\hline Amostras & CAC & $\begin{array}{c}\text { Proteína } \\
(\%)\end{array}$ \\
\hline SPI 1 & 1,25 & 10 \\
SPI 2 & 1,00 & 5,86 \\
WPC 1 & 0,75 & 30 \\
WPC 2 & 0,85 & 20 \\
\hline
\end{tabular}

*SPI é a mistura da proteína de soja com maltodextrina; WPC é a mistura de proteína de soro com maltodextrina.

\subsubsection{Secagem por atomização}

As amostras foram submetidas à secagem por atomização em um mini spray dryer (modelo B-290, marca Büchi, Suiça), com bico atomizador com orifício de $0,7 \mathrm{~mm}$ de diâmetro e pressão do compressor ajustada em 6 bar. Os parâmetros de operação do equipamento foram: temperatura do ar de secagem fixada em $140{ }^{\circ} \mathrm{C}$, vazão de alimentação de $2 \mathrm{~mL} / \mathrm{min}$ e fluxo de ar de 500 $\mathrm{L} / \mathrm{h}$. As análises de isotermas de sorção, pegajosidade e estabilidade foram realizadas em triplicata.

\subsubsection{Isotermas de sorção}

As isotermas de sorção dos sucos em pó foram determinadas a 5,25 e $35{ }^{\circ} \mathrm{C}$, pelo método estático gravimétrico (JOWITT et al., 1983). Sete soluções saturadas ( $\mathrm{LiCl}$, $\mathrm{CH}_{3} \mathrm{COOK}, \quad \mathrm{MgCl}_{2}, \quad \mathrm{~K}_{2} \mathrm{CO}_{3}, \quad \mathrm{Mg}\left(\mathrm{NO}_{3}\right)_{2}$, $\mathrm{NaNO}_{2}$ e $\mathrm{NaCl}$ ) foram usadas para obter diferentes umidades relativas numa faixa de 0,11 a 0,76 . As amostras foram armazenadas em estufa com temperatura controlada.

\subsubsection{Pegajosidade}

A pegajosidade foi determinada de acordo com o método descrito por Telis e Martinez-Navarrete (2010). Testes de compressão mecânica foram conduzidos em um texturômetro Texture Analyzer TAXT2 ${ }^{\text {TM }}$ (Stable Micro Systems Ltd., U.K.), utilizando-se um probe cilíndrico de $10 \mathrm{~mm}$ de diâmetro. As amostras foram comprimidas por uma distância de $3 \mathrm{~mm}$ a uma taxa constante de $0,1 \mathrm{~mm} / \mathrm{s}$.

\subsubsection{Estabilidade frente à luz}

Amostras do suco em pó foram acondicionadas em embalagens de polietileno de baixa densidade seladas a vácuo e colocadas em uma estufa com temperatura controlada de $25{ }^{\circ} \mathrm{C}$, sob incidência de luz a 3500 lux com uso de lâmpadas fluorescentes de $15 \mathrm{~W}$. As amostras foram distribuídas uniformemente, assegurando que a iluminação incidisse sobre todo material igualmente, por um período de 90 dias, retirando-se amostras para avaliação após 2 , $4,7,15,30,45,60$ e 90 dias de 
armazenamento. Para estudo da estabilidade o suco de uva em pó foi avaliado quanto ao teor de antocianinas totais, umidade e cor.

As antocianinas totais foram determinadas por espectrofotometria. As antocianinas foram extraídas com $95 \%$ de etanol/1.5 N HCl (85:15, v:v), de acordo com o procedimento descrito por Francis (1982). A absorbância foi medida em um espectrofotômetro UV-vis (SP-220, Biospectro) em $520 \mathrm{~nm}$. O conteúdo de antocianinas totais $(\mathrm{mg} / \mathrm{L})$ foi calculado através da Equação 1.

$$
\operatorname{Antocianinas}(m g / L)=\frac{A \times P M \times F D \times 10^{3}}{\varepsilon \times L}
$$

onde A é a absorbância a $520 \mathrm{~nm}, \mathrm{PM}$ é o peso molecular correspondente a malvidina-3glicosídeo, FD é o fator de diluição, $\varepsilon$ é o coeficiente de absorção molar, L é a largura da cubeta e $10^{3}$ é o fator de conversão de $\mathrm{g}$ para $\mathrm{mg}$.

A umidade das amostras foi determinada, em triplicata, com secagem em estufa a vácuo (Marconi, modelo MA 030) a $70^{\circ} \mathrm{C}$ por 48 horas.

A análise de cor foi realizada em colorímetro Hunter (D25-2, HunterLab, USA) com observador a $10^{\circ}$ e iluminante D 65 . Foram determinados o parâmetro L (luminosidade) e as coordenadas cromáticas a $(+\mathrm{a}=$ vermelho; $-\mathrm{a}=$ verde $)$ e $\mathrm{b}(+\mathrm{b}=$ amarelo, $-\mathrm{b}=\mathrm{azul}$ ). Esses parâmetros foram utilizados para calcular a diferença global de cor $(\Delta \mathrm{E})$, de acordo com a Equação 2.

$$
\Delta E=\sqrt{\left(L_{0}-L\right)^{2}+\left(a_{0}-a\right)^{2}+\left(b_{0}-b\right)^{2}}
$$

\section{RESULTADOS E DISCUSSÃO}

\subsection{Isotermas de sorção}

As Figuras 1 e 2 mostram as curvas de sorção das amostras compostas por SPI e MD; WPC e MD, respectivamente.

Figura 1 - Isotermas de sorção das amostras SPI 1 e SPI 2, em função da temperatura.

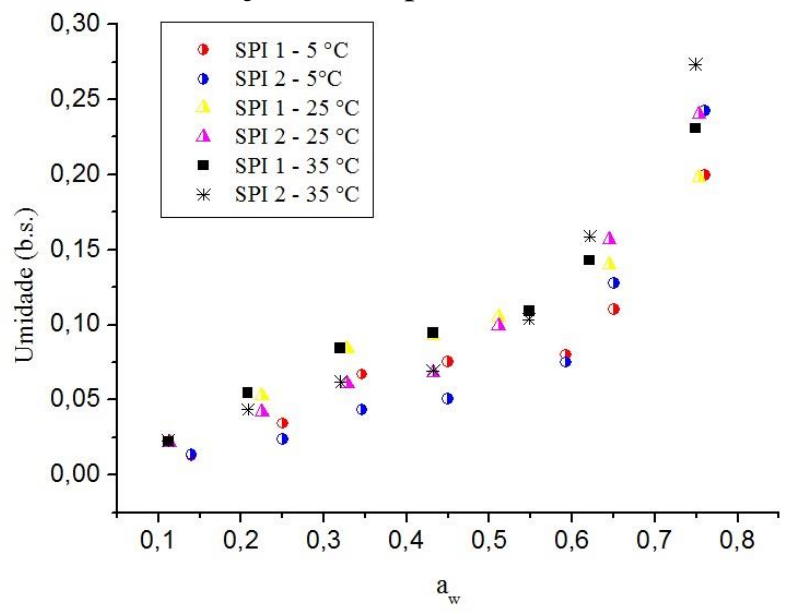

Figura 2 - Isotermas de sorção das amostras WPC 1 e WPC 2, em função da temperatura.

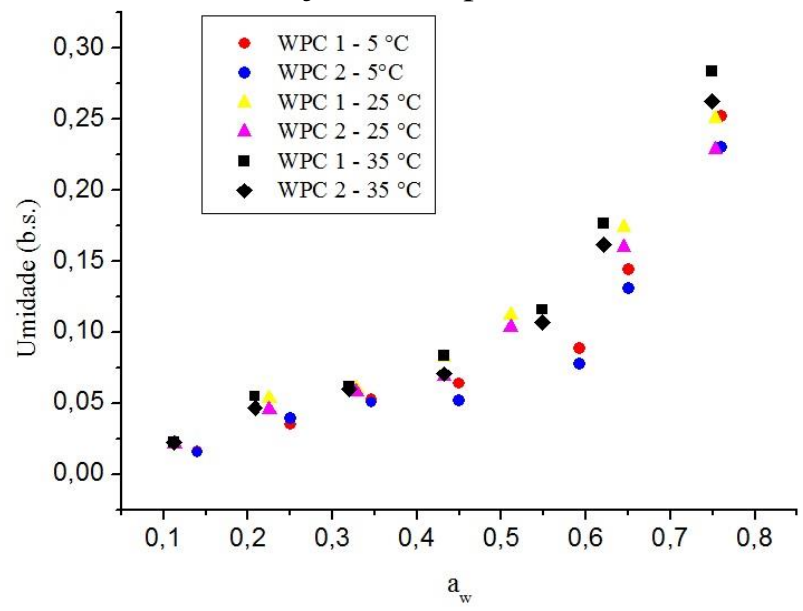

Observamos, através das Figuras 1 e 2, que as umidades das amostras para baixas atividades de água $\left(\mathrm{a}_{\mathrm{w}} \leq 0,2\right)$ permanecem próximas. Esse comportamento está relacionado ao fato de que em ambientes com baixa umidade relativa há menor gradiente de pressão de vapor entre o produto desidratado $\mathrm{e} \mathrm{o}$ ar ambiente, propiciando maior estabilidade dos pós. Comportamento semelhante foi observado por Barbosa (2010). 
Para atividades de água intermediárias $\left(0,2<a_{w}<0,5\right)$, a umidade da amostra SPI 1 aumentou perceptivelmente em comparação às outras amostras, sendo maior com 0 aumento da temperatura de armazenamento. Tal resultado é explicado pela maior porcentagem de proteína isolada de soja na mistura dos carreadores em relação à amostra SPI 2. Vale ressaltar que a proteína isolada de soja possui maior adsorção em relação à proteína concentrada de soro, principalmente em baixas umidades relativas, como avaliado em análises anteriores. Já as umidades das amostras SPI 2, WPC 1 e WPC 2 permanecem ligeiramente próximas. $E m \mathrm{a}_{\mathrm{w}} \geq$ 0,5, a umidade das amostras SPI 2 e WPC 1 foi maior em relação as outras amostras, enquanto a umidade da amostra SPI 1 se manteve menor, mostrando uma maior estabilidade em relação à absorção de água. A baixa umidade da amostra SPI 1 pode estar relacionada a maior concentração de maltodextrina no sistema. De acordo com Ferrari, Ribeiro e Barros (2012), o alto teor de maltodextrina resulta em pós menos higroscópicos.

A adsorção de água foi proporcional à temperatura, ou seja, quanto maior a temperatura de armazenamento, maior a umidade final da amostra. Esse comportamento não foi observado para umidades relativas menores que $20 \%$, assim como observado por Fiorentin et al. (2010).

\subsection{Pegajosidade}

As Figuras 3 e 4 mostram os dados de pegajosidade obtidos para as amostras SPI e WPC, respectivamente, em função da temperatura.

Figura 3 - Análise de pegajosidade das amostras SPI 1 e 2, em função da temperatura.

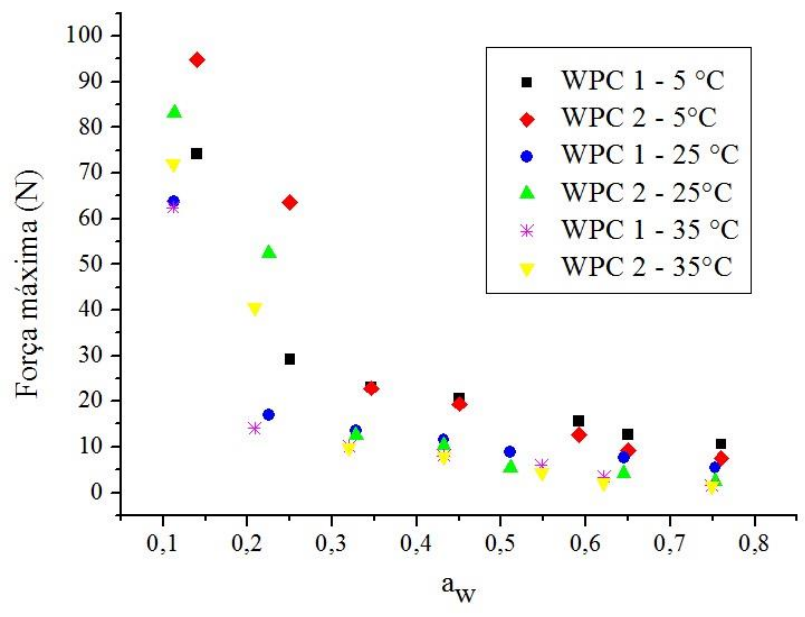

Figura 4 - Análise de pegajosidade das amostras WPC 1 e 2, em função da temperatura.

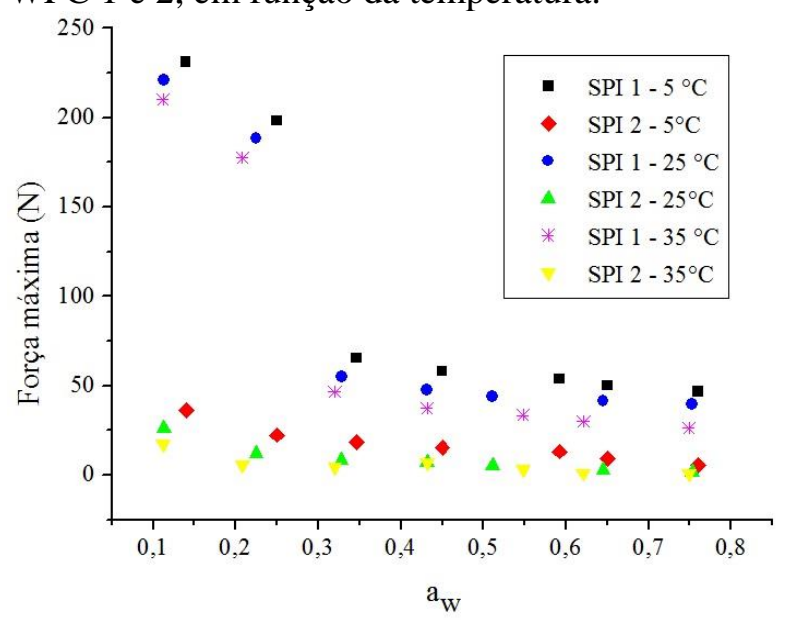

A força máxima do suco em pó apresentou uma forte relação com a atividade de água. A amostra SPI 1 foi a menos pegajosa nas três temperaturas, principalmente em $a_{w}<0,2$. Esse resultado se deve à alta concentração de maltodextrina, o que torna a amostra menos higroscópica e, consequentemente, menos pegajosa. Resultados semelhantes foram encontrados por Tonon, Brabet e Hubinger (2009) e Ferrari, Ribeiro e Barros (2012). As outras três amostras apresentaram pegajosidade muito semelhante entre si em $\mathrm{a}_{\mathrm{w}}$ acima de 0,3. Vale ressaltar que a força máxima da amostra SPI 1, para umidades relativas de aproximadamente $75 \%$, foi maior do que a força máxima das amostras SPI 2, WPC 1 e 
WPC 2 em umidades relativas de $20 \%$ ou maiores, ou seja, as outras amostras apresentaram-se muito mais pegajosas em relação a SPI 1.

Assim, para $\mathrm{a}_{\mathrm{w}}<0,2$, as forças máximas atingidas durante as compressões foram elevadas, principalmente para a amostra SPI 1, que apresentou uma força inicial de 221,25 $\mathrm{N}$, enquanto as outras amostras apresentaram uma força inicial abaixo de $100 \mathrm{~N}$. Enquanto que, para $a_{w}>0,2$, as amostras se apresentaram mais pegajosas, devido, também, à alta concentração de açúcares e alta higroscopicidade, resultando em menor força de compressão e aderência de amostra no equipamento durante a descompressão.

Analisando a pegajosidade em função da temperatura, para cada amostra, verificouse que a pegajosidade foi proporcional a higroscopicidade, ou seja, quanto menor a temperatura, menor a higroscopicidade e, portanto, menor a pegajosidade, independente da umidade relativa do ambiente de armazenamento.

\subsection{Estabilidade das antocianinas frente à luz}

A Figura 5 mostra a quantidade de antocianinas e a Figura 6, a umidade do suco de uva em pó durante 90 dias de armazenamento, sob a incidência de luz.

Figura 5 - Degradação de antocianinas frente à luz.

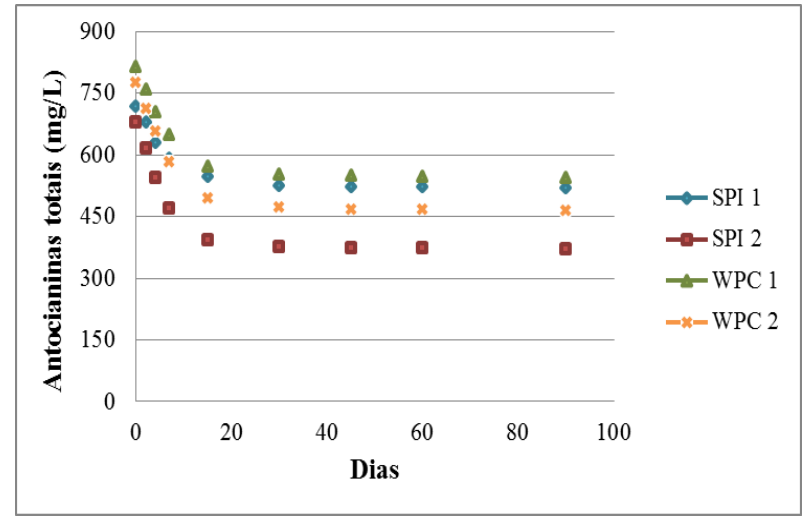

Figura 6 - Umidade, em base seca, das amostras expostas à luz.

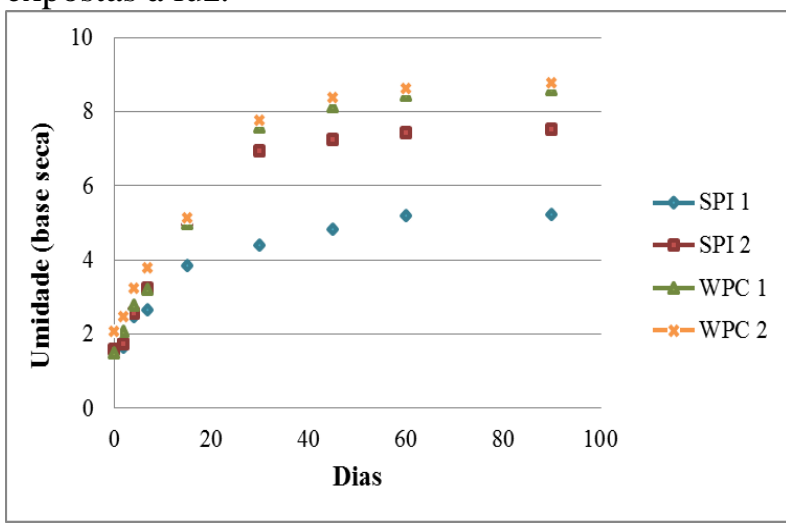

Na Figura 5, percebe-se que há uma alta degradação de antocianinas durante os primeiros 15 dias de armazenamento. A amostra microencapsulada com SPI 2, foi menos estável, perdendo $45 \%$ da quantidade inicial de antocianinas, enquanto a amostra WPC 2 perdeu $40 \%$ e a WPC $1,33 \%$. A amostra que apresentou menor degradação das antocianinas foi a SPI 1, a qual teve uma perda de $28 \%$, se mostrando o sistema encapsulante mais efetivo para estabilizar o composto bioativo durante o armazenamento.

A amostra SPI 1 também apresentou boa estabilidade em relação à umidade (Figura 6), a qual absorveu menos água durante o armazenamento. A amostra WPC 2 foi a que apresentou maior absorção de umidade, juntamente com a amostra WPC 1. Provavelmente as amostras WPC 1 e WPC 2 apresentaram valores tão próximos de umidade de equilíbrio devido à semelhança na composição do agente carreador. A variação global da cor durante o armazenamento está apresentada na Tabela 2. 
Tabela 2 - Análise de cor das amostras expostas à luz por 30 dias.

$\Delta \mathbf{E}$

\section{$\begin{array}{lllll}\text { Amostras } & \text { SPI } 1 & \text { SPI } 2 & \text { WPC } 1 & \text { WPC } 2\end{array}$}

\begin{tabular}{ccccc}
\hline $\mathbf{0}$ & - & - & - & - \\
$\mathbf{2}$ & 0,94 & 1,22 & 8,12 & 0,78 \\
$\mathbf{4}$ & 1,17 & 6,66 & 10,81 & 1,14 \\
$\mathbf{7}$ & 1,41 & 7,53 & 9,89 & 1,89 \\
$\mathbf{1 5}$ & 1,74 & 2,37 & 6,38 & 2,32 \\
$\mathbf{3 0}$ & 2,89 & 12,07 & 7,85 & 10,43 \\
$\mathbf{4 5}$ & 3,00 & 12,16 & 7,93 & 10,48 \\
$\mathbf{6 0}$ & 3,06 & 12,24 & 7,98 & 10,52 \\
$\mathbf{9 0}$ & 3,09 & 12,29 & 8,02 & 10,54 \\
\hline
\end{tabular}

Para calcular a variação global da cor foram comparados os resultados de cor no tempo 0 (início do armazenamento) e em cada tempo de armazenamento.

Para avaliar a diferença de cor entre as amostras, seguimos os critérios estabelecidos por Obón et al. (2009). Segundo os autores, $\Delta \mathrm{E}$ entre $0-1,5$ é muito pequena, sendo considerada quase idêntica através da observação visual, $\Delta \mathrm{E}$ entre $1,5-5$ a diferença de cor pode ser distinguida, e, $\Delta \mathrm{E}$ maior do que 5 a diferença de cor é evidente.

Após 15 dias de armazenamento a diferença na cor da amostra SPI 1 pode se notada, porém, durante todo o período de exposição, ela foi inferior a 5, o que demonstra uma boa estabilidade do material para manter a cor do produto. Já a amostra WPC 1 foi a que apresentou maior variação na sua coloração, com $\Delta \mathrm{E}$ maior que 5, sofrendo uma diferença notável na coloração, para qualquer tempo de exposição à luz. As amostras SPI 2 e WPC 2, apresentaram $\Delta \mathrm{E}$ maior que 5 a partir do $4^{\circ}$ dia e do $30^{\circ}$ dia de armazenamento, respectivamente.
A amostra SPI 1 apresentou uma diminuição do parâmetro $\mathrm{L}^{*}$, indicando um escurecimento da amostra após exposição à luz; há, também, um efeito nos parâmetros a* e b*, mostrando a diminuição da intensidade das colorações vermelha e azul, respectivamente. A amostra SPI 2 apresentou notável escurecimento após 30 dias de exposição à luz, com menos intensidade das colorações vermelha e azul. Para a amostra WPC 1, há aumento no parâmetro $\mathrm{L}^{*}$, indicando a descoloração da amostra com redução na intensidade das colorações vermelha e azul. Para a amostra WPC 2, houve diminuição de $\mathrm{L}^{*}$, indicando escurecimento da amostra, principalmente após 30 dias de exposição à luz; o parâmetro $a^{*}$ se manteve estável, indicando estabilidade da coloração vermelha, porém o parâmetro b* apresentou diminuição, indicando menor intensidade da coloração azul.

Stringheta (1991) estudou a estabilidade de antocianinas presentes no capim e obteve resultados que comprovam o efeito degradante da luz nesses compostos. Palamidis e Markakis (1975) observaram que a presença de luz acelerou a destruição das antocianinas em bebidas carbonatadas, coloridas com antocianinas extraídas da polpa da uva. O tempo de meia-vida das antocianinas a $20^{\circ} \mathrm{C}$, armazenadas no escuro foi de 416 dias, diminuindo para 197 dias quando as bebidas foram expostas à luz ambiente. Amr e Al-Tamini (2007) também verificaram que a luz tem um efeito negativo sobre a estabilidade das antocianinas durante o armazenamento, especialmente na presença de açúcar, como é o caso do suco de uva. Maier et al. (2009) estudou a estabilidade de antocianinas sob luz néon e no escuro durante 24 semanas. Eles verificaram que a exposição à luz diminuiu consideravelmente o teor de compostos fenólicos e antocianinas durante o armazenamento.

Analisando-se todos os dados obtidos para o estudo da estabilidade, percebe-se que 
a amostra SPI 1 se mostrou mais estável frente à exposição à luz, tendo a menor degradação de antocianinas, o menor ganho de umidade e a menor diferença de cor em relação ao pó após a secagem.

\section{CONCLUSÕES}

O uso de maltodextrina com proteína de soja ou de soro de leite se mostrou promissor e viável, melhorando as características de higroscopicidade e textura do suco em pó. A maior concentração dos agentes carreadores resultou em maior estabilidade dos pós, uma característica desejável de um produto que deve ter uma longa vida de prateleira.

A amostra SPI 1 apresentou menor higroscopicidade, pegajosidade e maior estabilidade frente à luz, o que demonstra que essa combinação de carreadores, na concentração e proporção usada, é eficiente para obter suco de uva em pó com qualidade e boa estabilidade.

\section{REFERÊNCIAS}

AMR, A.; AL-TAMIMI, E. Stability of the Crude Extracts of Ranunculus Asiaticus Anthocyanins and their use as Food Colourants. International Journal of Food Science and Technology, v.42, p.985-991, 2007.

BARbosA, S. J. Qualidade de Suco em Pó de Mistura de Frutas Obtido por Spray Drying. 2010. 122p. Dissertação (Magister Scientiae). Universidade Estadual de Montes Claros, Minas Gerais, 2010.

CHARVE, J.; REINECCIUS, G. A. Encapsulation Performance of Proteins and Traditional Materials for Spray Dried Flavors. Journal of Agricultural and Food Chemistry, v.57, n.6, p.2486-2492, 2009.
FERRARI, C. C.; RIBEIRO, C. P.; AGUIRRE, J. M. Secagem por Atomização de Polpa de Amora-preta Usando Maltodextrina como Agente Carreador. Brazilian Journal Food Technology, v.15, n.2, p.157-165, 2012.

FIORENTIN, L. D.; MENON, B. T.; BARROS, S. T. D.; PEREIRA, N. C.; LIMA, O. C. M.; MODENES, A. N. Isotermas de Sorção do Resíduo Agroindustrial Bagaço de Laranja. Revista Brasileira de Engenharia Agrícola e Ambiental, v.14, n.6, p.653-659, 2010.

FRANCIS, F. J. Analysis of anthocyanins. In: MARKAKIS, P. (Ed.). Anthocyanins as Food Colors. New York: Academic Press, 1982.

JOWITT, R.; ESCHER, F.; HALLSTOM, B.; MEFFERT, H. F. T.; SPIESS, W. E. L.; VOS, G. Physical Properties of Foods. London and New York: Applied Science Publishers, 1983.

KANDANSAMY, K.; SOMASUNDARAM, P. D. Microencapsulation of colors by spray drying - A review. International Journal of Food Engineering, v.8, n.2, art.1, 2012.

MADENE, A.; JACQUOT, M.; SCHER, J.; DESOBRY, S. Flavour encapsulation and controlled release - a review. International Journal of Food Science and Technology, v. 41, p. 1-21, 2006.

MAIER, T.; FROMM, M.; SCHIEBER, A.; KAMMERER, D.R.; CARLE, R. Process and Storage Stability of Anthocyanins and nonanthocyanin Phenolics in Pectin and Gelatin Gels Enriched with Grape Pomace Extracts. European Food Research and Technology, v.104, p.732-739, 2009. 


\section{ENEMP \\ $\rightarrow 0015$ \\ DE SISTEMAS PARTICULADOS \\ São Carlos - SP}

NESTERENKO, A.; ALRIC, I.; SILVESTRE, F.; DURRIEU, V. Vegetable proteins in microencapsulation: A review of recent interventions and their effectiveness. Industrial Crops and Products, v 42, p. 469-479, 2013.

OBÓN, J. M.; CASTELLAR, M. R.; ALACID, M.; FERNÁNDEZ-LOPÉZ, J. A. Production of a Red-purple Food Colorant from Opuntia Stricta Fruits by Spray Drying and its Application in Food Model Systems. Journal of Food Engineering, v.90, p.471479, 2009.

PALAMIDIS, N.; MARKAKIS, P. Stability of Grape Anthocyanin in a Carbonated Beverage. Journal of Food Science, v.40, p.1047-1049, 1975.

REBELLO, L. P. G., LAGO-VANZELA, E. S., BARCIA, M. T., RAMOS, A. M., STRINGHETA, P. C., DA-SILVA, R., HERMOSÍN-GUTIÉRREZ, I. Phenolic composition of the berry parts of hybrid grape cultivar BRS Violeta (BRS Rubea $\times$ IAC 1398-21) using HPLC-DAD-ESI-MS/MS. Food Research International, v.54, p. 354366,2013

STRINGHETA, P. C. Identificação da Estrutura e Estudo da Estabilidade das Antocianinas Extraídas da Inflorescência de Capim Gordura (Mellinis minutuflora, Pal de Beauv.). 1991. 138p. Tese (Doutorado em Ciência e Tecnologia de Alimentos). Universidade Estadual de Campinas, São Paulo, 1991.

TELIS, V. $\quad$ R. $\quad$ N.; MARTÍNEZNAVARRETE, N. Application of compression test in analysis of mechanical and color changes in grapefruit juice powder as related to glass transition and water activity. LWT - Food Science and Technology, v. 43, p. 744-751, 2010.
TONON, R. V.; BRABET, C. HUBINGER, M. D. Influência da Temperatura do ar de Secagem e da Concentração de Agente Carreador sobre as Propriedades Físicoquímicas do Suco de Açaí em Pó. Ciência e Tecnologia de Alimentos, v.29(2), p.444450, 2009.

BRASIL. União Brasileira de Vitivinicultura. Comercialização de vinhos e derivados. Rio Grande do Sul, maio de 2015. Disponível em: <www.uvibra.com.br>. Acesso em: 30 maio 2015.

\section{AGRADECIMENTOS}

Os autores agradecem ao Conselho Nacional de Desenvolvimento Científico e Tecnológico (Processo: 119931/2013-3), a Fundação de Amparo à Pesquisa do Estado de São Paulo (Processo: 2012/09074-4) e EMBRAPA - (Jales, SP, Brazil). 